\title{
The Importance of Context and the Effect of Information and Deliberation on Opinion Change Regarding Environmental Issues in Citizens' Juries
}

\author{
Andrew G.H. Thompson ${ }^{1, *(\mathbb{D})}$, Oliver Escobar ${ }^{1}{ }^{\mathbb{D}}$, Jennifer J. Roberts ${ }^{2}$, Stephen Elstub ${ }^{3}$ \\ and Niccole M. Pamphilis 4 (D) \\ 1 School of Social and Political Science, University of Edinburgh, 15a George Square, Edinburgh EH8 9LD, UK; \\ oliver.escobar@ed.ac.uk \\ 2 Civil and Environmental Engineering, University of Strathclyde, 75 Montrose Street, Glasgow G1 1XJ, UK; \\ jen.roberts@strath.ac.uk \\ 3 School of Geography, Politics and Sociology, Newcastle University, Henry Daysh Building, \\ Newcastle upon Tyne NE1 7RU, UK; stephen.elstub@newcastle.ac.uk \\ 4 School of Social and Political Sciences, University of Glasgow, Adam Smith Building, Bute Gardens, \\ Glasgow G12 8RT, UK; Niccole.Pamphilis@glasgow.ac.uk \\ * Correspondence: andrew.thompson@ed.ac.uk
}

check for

updates

Citation: Thompson, A.G.H.; Escobar, O.; Roberts, J.J.; Elstub, S.; Pamphilis, N.M. The Importance of Context and the Effect of Information and Deliberation on Opinion Change Regarding Environmental Issues in Citizens' Juries. Sustainability 2021, 13, 9852. https://doi.org/10.3390/ su13179852

Academic Editor: Corrado Battisti

Received: 24 June 2021

Accepted: 27 August 2021

Published: 2 September 2021

Publisher's Note: MDPI stays neutral with regard to jurisdictional claims in published maps and institutional affiliations.

Copyright: (c) 2021 by the authors. Licensee MDPI, Basel, Switzerland. This article is an open access article distributed under the terms and conditions of the Creative Commons Attribution (CC BY) license (https:// creativecommons.org/licenses/by/ $4.0 /)$.

\begin{abstract}
Citizens' juries have become a popular method for engaging citizens in deliberation about complex public policy issues, such as climate action and sustainable development. Empirical evidence routinely indicates that jurors change their minds throughout the process. What is less clear is when and why this occurs and whether the causes are consistent across juries that consider the same topic but are situated within different contexts. We present evidence of opinion change in citizens' juries through a natural experiment, contrasting three local contexts of onshore windfarm development in Scotland; viz. existing, planned, and absent. Jurors' individual opinions of climate change, wind energy, and windfarms were measured through questionnaires at four time points: the start, following information-giving, reflection, and deliberation. Statistical examination of jurors' responses, through paired sample $t$-tests, Wilcoxon sign-tests, and Generalised Least Squares regression, reveals to what extent substantive changes were associated with different phases and locational contexts. In all three juries, opinion change occurs throughout the process, on different topics, and to different degrees. While the information phase consistently influences jurors' opinions the most, jury composition affects the magnitude and direction of opinion change, with outcomes contingent on contexts. Our findings are important for informing how mini-publics are designed and used to inform environmental policy-making at different scales.
\end{abstract}

Keywords: political participation; citizens' juries; deliberation; natural experiment; opinion change; sustainability; windfarms; Scotland

\section{Introduction}

Citizen engagement is critical to enable the complex socio-economic transformations required for a sustainable future [1]. Indeed, the 2030 Agenda for Sustainable Development presents a clear mandate for public participation, outlining a shared vision to "ensure responsive, inclusive, participatory and representative decision-making at all levels" (Indicator 16.7) [2]. Mini-publics are now widely used in policymaking practice as a means of bringing citizens into processes of framing, advising on, or deciding about, complex public policy issues such as climate action and environmental health from local to global governance [3], exemplified by the rise of climate assemblies [1]. A key aim of the mini-publics is to realise norms of deliberative democracy [4] and to foster its long-term sustainability, as argued in this special issue of the journal by Strandberg et al. [5], in relation to 
mixed deliberations between citizens and politicians, and by Kulha et al. [6], in relation to environmental intergenerational fairness.

A central tenet of the normative theory of deliberative democracy is that participants should enter a discussion with an open mind, be willing to reflect upon their opinions in light of reasons offered by others, and therefore remain open to changing their opinions accordingly. Only with open minds can the 'forceless force of the better argument' [7] (p. 108) have any chance of prevailing. These mindsets alone realise the epistemic and prudential benefits that justify a deliberative approach to democracy. However, it is evident that, firstly, there are many causes of opinion change other than deliberation [8]. Secondly, and more concerning from a deliberative democracy perspective, many of these causes are not compatible with the norms of deliberative democracy, such as manipulation and bias. We, therefore, need a greater understanding of the role deliberation plays in generating opinion reflection and change, and the potential conditioning effects of the context in which it occurs.

Much of the research to date on this issue has been conducted through mini-publics, that is, participatory processes where citizens are selected through a civic lottery (e.g., stratified random sampling) and supported to engage in informed deliberation to produce recommendations or decisions on a public issue. A key reason for their popularity is that mini-publics are artificially designed to create environments conducive to learning, open-mindedness and deliberation that stimulate opinion reflection. Indeed, empirical evidence from mini-publics routinely indicates that participants do indeed reflect on, revise and modify their opinions during the process [4]. However, the evidence from these studies is far from conclusive with regard to the relationship between deliberation and opinion reflection and change. In particular, it is not clear which aspect(s) of the process is associated with opinion change and whether the findings are consistent across mini-publics in different contexts. This is important for assessing the compatibility of opinion change with the norms of deliberative democracy, mini-public design, and the application and use of mini-publics. If mini-publics are to guide political choices amongst the public and policymakers, as some have advocated [9], then we must understand what shapes the opinions participants have at the end of the process and ascertain if this is consistent within different contexts, or responsive to those contexts, so we can discuss the level of trust and influence that should be afforded to these opinions and the deliberative process. Environmental governance offers an excellent context to study these issues because deliberation must encompass local, national, and global considerations.

This paper analyses three standardised citizens' juries conducted in Scotland on the contested topic of onshore windfarms. They were held contemporaneously in locations with different levels of exposure to local windfarms. This was organised as a research project rather than an official policy process, but it was nonetheless designed to inform Scottish debate about onshore windfarms, deliberative public engagement, and democratic innovations. Despite it being a research project, it aims to offer insights of relevance to environmental governance, especially given the proliferation of mini-publics on this topic, and the need to understand better the dynamics within these processes. Nonetheless, due to the limitations of size and context, this study is only one of several that will be needed to generate reliable and coherent theory for the purposes of policy.

The task for the jurors was to consider: 'What should be the key principles for deciding about windfarm development, and why?' Accordingly, participants were invited to engage with long-term considerations regarding policy, energy generation, and climate change, topics that have been at the centre of Scotland's debate on environmental governance (Further details are provided on the project website: https:/ / www.climatexchange.org. uk/research/projects/citizens-juries-on-wind-farm-development-in-scotland/ (accessed on 26 August 2021)). Here, we analyse if, how, and when jurors change their opinions during the course of the process in three different locations, using findings from survey research, supplemented by ethnographer and evaluator fieldnotes. Consequently, our analysis contributes to testing the normative claims made by deliberative democrats about 
opinion change, and, moreover, to debates about the contribution citizens' juries can make to institutionalising deliberative democracy in environmental governance, given various contextual conditions. In our research, we were interested in testing whether opinions about the key principles for wind farm development were consistent in conclusion for Scotland as a whole, irrespective of location, or whether these contextual differences were reflected in opinion divergence.

The paper is divided into five sections. The first two consider the theories and empirical studies of opinion change in relation to deliberative democracy and citizens' juries, respectively. The third section outlines the methodological aspects of our study, leading into the fourth section which presents the findings. The fifth section discusses the results in relation to what is already known and offers conclusions.

\subsection{Deliberative Democracy and Opinion Change}

Deliberative democrats believe opinions should be open to development during the political process, through deliberation, rather than concluded prior to it. This implies that interlocutors need to be willing to change their minds. Indeed, for Chambers [10] (p. 318) 'a central tenet of all deliberative theory is that deliberation can change minds and transform opinions', while for Elster [11] (p. 6) 'the transformation of preferences through rational deliberation is the ostensible goal of arguing'. The normative argument is that through engaging in public deliberation participants' opinions do not just change, they become more 'informed, enlightened, and authentic' [12] (p. 1) (see also [13]). Consequently, opinion change is not necessarily desirable per se, as people might change their minds due to 'conscious manipulation' or 'unconscious bias' [8] (p. 321). For example, empirical research indicates that, when participating in collective discussion, people will change their opinions due to 'inequalities, biases, and manipulatory strategies' [14] (p. 380), such as the employment of particular frames [15]. Further, opinions may change to comply with majorities to achieve conformity [16], or through being 'undermined by group norms' [17] (p. 657), due to group polarization [18] and due to cognitive constraints [19], all of which are problematic for deliberative theory [20]. Therefore, when people change their minds, if it is to be authentic and legitimate, it must be due to the 'mechanisms specified in the normative theories' of deliberative democracy [21] (p. 1). Ultimately, the distinction is between manipulation, which is bad for deliberative democracy, and non-coercive persuasion, which is good [22]. Here we focus on two of these mechanisms related to persuasion; information gains and reasoning.

During collective deliberation, participants pool the relevant information they have on the issue at hand, leading to information gains for most participants [23,24], which can, in turn, lead to changes in opinion [25]. This is a significant benefit of collective deliberation, but, for Rosenberg [26] (p. 109), what is more important, from a deliberative point of view, is whether the increased information improves 'the quality of their reasoning'. Therefore, it is not just receiving more information that should induce opinion reflection and change, but the process of public reasoning more broadly. For deliberative democrats, opinions, preferences and attitudes are adaptable to reason and, through consideration of differing reasons, existing opinions can be transformed and new opinions formed: 'democratic deliberation is publicly reasoned in the sense that people offer reasons in support of their opinions and perspectives, hope they will prove convincing to others and expect these reasons, and these reasons alone, to be the motivating force of people accepting them or not' $^{\prime}$ [27] (p. 69). In sum, we need both information and reasons to form coherent opinions between available options [25].

Deliberative democrats do accept, however, that participating in collective deliberation will not always cause opinion change. On reviewing the new information and considering the reasons others provide, a participant may decide that their initial opinions were still appropriate and publicly defensible [23]. This is legitimate from a deliberative perspective, providing participants entered the deliberative process with an open mind $[13,23,28,29]$. Therefore, a non-coercive reflection is required, rather than opinion change per se [13]. 
Despite this acknowledgement, there are good reasons why we expect deliberation to affect opinion [14]. Firstly, citizens often enter deliberation with tentative and incomplete views $[24,30]$. This is especially the case if the opinions of those deliberating are unlikely to be consequential. Rational choice theory implies that citizens would not have the motivation to become informed about an issue if their influence is likely to be very limited [31]. Secondly, participants in inclusive public deliberation should be exposed to different kinds of information and arguments to what is usual for them [23,32,33], which encourages them to see issues in a different light and may affect their views [25]. Thirdly, in the course of devising and articulating public reasons to justify their position, participants may adapt their opinions [29,34].

For others, public deliberation is not always required if it is accepted that uncoerced opinion reflection is key [35], as 'deliberation within' can also generate public reasoning because other opinions can be made 'imaginatively present' through individuals conducting 'a wide-ranging debate within their heads' [36] (pp. 63-64). This involves an 'internal reflective process' amongst participants where they put themselves in the place of the other [37] (p. 81). Indeed, we weigh up reasons and attempt to understand the reasons of others, all through internal reflection, even when we do engage in collective deliberation [35], which may occur between, not necessarily within, deliberations [38].

The problem is that, despite the importance of open-mindedness, opinion reflection and opinion change for deliberative democracy, there are significant gaps in our understanding about the connection between these [14].

\subsection{Citizens' Juries and Opinion Change}

Mini-publics are the most lauded device for institutionalising deliberative democracy but have also been employed by researchers seeking to test the normative claims of deliberative democracy [39], particularly those relating to opinion change [32,33]. They are seen as an opportunity for citizens to deliberate on important and contentious issues, and to reflect on and revise their opinions in light of deliberation. There are various types of mini-public, including planning cells, consensus conferences, deliberative polls, and citizens' assemblies, but here we focus on citizens' juries. Citizens' juries are typically organised into three sequential phases: an 'information phase' where witnesses provide a range of evidence and advocacy of relevant information and positions as a supplement to the sharing of information amongst jurors; a 'deliberation phase' where citizens discuss the merits of different options and reach a collective decision; and a 'reflection phase' which occurs in between. It is important to note that all three phases can be 'reflective' and that the 'information' phase is discursive too, as it includes the questioning of the witnesses and informal talk, but it can still be differentiated from the more formal deliberation phase where jurors strive to reach a collective viewpoint on the issue at hand [35].

The significant focus that mini-publics have been afforded by deliberative democrats 'is based on the premise that the norms of deliberative democracy are so difficult to achieve in practice that it will not occur naturally, so the conditions ... need to be artificially created' [40] (p. 7); [32]. For practical reasons, stratified random sampling is employed to recruit a diverse selection of citizens, ensuring that each person has an equal chance of being selected within their stratum. The aim is to assemble a 'deliberative microcosm' of the population that is 'small enough to be genuinely deliberative and representative enough to be genuinely democratic' [41] (p. 11). Most studies of this nature are very small in order to achieve these deliberative aims; e.g., Strandberg et al.'s use of two citizens' forums with 17 and 18 people (21 citizens and 14 politicians) [42]; Baccaro et al.'s twelve discussion groups of 9 to 11 students per group [20]; and the use of 57 discussion groups by Gastil et al. [43], with only 3 to 6 students per group. However, given the small number of participants (typically 12-25 [44]) in citizens' juries, they are not intended to be statistically representative of the population, but 'demographically diverse' [45] (p. 96). The hope is that this will also lead to a diversity of starting positions on the issue, although the likelihood of this is disputed [46]. Because the sampled citizens are probably not partisan 
stakeholders on the issue, they tend not to have strong pre-deliberative opinions on the issue being discussed and are, therefore, more likely to enter the process with an open mind, amenable to reflection and opinion change [4].

Opinion change does appear to be commonplace in citizens' juries [44,47-51]. However, most of these studies are based on surveys of the jurors' attitudes before and after the process. Therefore, although they show that opinions do change, the results cannot fully explain when and why the participants changed their minds. Adopting an experimental design, Esterling et al. [52] randomised 2793 participants to small discussion tables in 19 Town Halls in the USA, with an average of about 8 people per table. By separating immediate intuitions, measured through questions of latent ideology, and deliberate, analytical thinking, based on topic-specific questions, namely System 1 versus System 2 thinking [53], they were able to show that argument-based persuasion, rather than polarisation by ideology, influenced participants' opinions. It was most likely for opinions to change when the discussions were perceived as well-informed, although no attempt was made to separate the contributions of information and deliberation.

Strandberg and Berg [42] found that facilitated rather than non-facilitated deliberation prevented opinion polarisation and may relate to aggregate-level change and the magnitude of change at the individual level (see also [20,54]). Himmelroos and Christensen [55] also found in their quasi-experimental study that deliberation moved people away from the extremes, rather than any evidence of group dynamics changing opinions, although they admit it might be due to information rather than deliberation per se. In contrast, Herne et al. [56] find that increased knowledge can cause polarisation at the individual level; it varies according to deliberative context, and deliberation in mini-publics can reduce polarisation at the aggregate level.

The evidence on opinion change from mini-publics in general, and citizens' juries in particular, has been criticised, as it is hard to prove that opinion change has been the result of the deliberative phase and not just the information provided, media coverage, discussion procedures adopted, or other political or psychological factors [20,32,57-60]. Indeed, research on deliberative polls could not identify any 'robust' predictor of opinion change [61]. In short, many of the existing studies on deliberation and opinion change fail to uncover 'the underlying opinion processes at work' [23] (p. 688).

Research on the 'Far North Queensland Citizens' Jury' in Australia attempted to find a resolution to this shortcoming [35]. Twelve jurors were surveyed at the beginning and end of the jury process, and once during the process between the information phase and the deliberation phase of the jury. The before and after analysis indicated that the jurors' opinions on the various policy options changed greatly, and 'the bigger change, by a wide margin, occurred in the minds of the jurors before the jury's formal discussion began' (i.e., before the deliberation phase), possibly in anticipation of forthcoming deliberations [35] (p. 634). Although the deliberation phase did produce opinion change, the changes within the information phase were substantially greater than those in the deliberative phase [35]. The jurors themselves also reported feeling that most impacts on any changes to their opinions occurred during the information phase (Ibid.). Goodin and Niemeyer [35] argue that these findings are not due to the fact that the information phase occurred first and lasted three times longer than the deliberation phase, because the opinion changes were not random, continuous, unidirectional, or proportional to the duration of the information and deliberation phases. Further, evidence from deliberative polls [62] supports the findings that information, rather than discussion, has the greatest effect on the magnitude of opinion change. The findings are also corroborated by the outcomes from citizens' assemblies in Canada that followed a discussion-information-discussion format and found that the information session was the most influential on participant attitudes [63].

Goodin and Niemeyer [35] do not conclude that opinion change in citizens' juries can simply be explained by information gains. After all, discussion did occur during the information phase, and the deliberative phase also led to opinion change. Furthermore, some psychological studies indicate that increased information is not a reliable source of 
opinion change in itself [64], while Sanders [61] finds that in deliberative polls there is no effect of knowledge gain on opinion change. Rather, Goodin and Niemeyer conclude that internal-reflexive processes of 'democratic deliberation within' are of central importance to the deliberative process, as it may alter 'the way people process ... information and hence (perhaps) what they think about the issue' [35] (p. 642). Furthermore, when receiving the information in the initial phase, the jurors did so in anticipation of having to deliberate later in the process, where they knew they would have to find a publicly defensible position and account for their views with reasons [35]. Again, this is consistent with other studies on deliberative polls, which indicate that knowledge gains of participants are enhanced by deliberation $[65,66]$ and that those who enter the process with the least knowledge change their opinions to the greatest extent [67]. That said, research from a mini-public held in Ireland in 2011 indicates that deliberation might still be crucial for opinion change [68] as it has different effects on opinion than information [69]. A control group was provided with the same information packs as the mini-public participants but did not go on to undertake collective deliberation. The control group did not undergo as much opinion change as the mini-public participants [68]. Clearly, further research is required to establish the cause(s) of citizen opinion change in mini-publics.

As Curato et al. [70] argue, deliberative transformation takes time and may not follow a linear path, with initial informational effects producing a cathartic change, which might later develop into deliberative opinions after further reflection [35]. Citizens' juries may be too short to enable the tracking of these deeper transformations. Moreover, a significant limitation of these studies is that they focussed on a one-off, isolated mini-public. Therefore, we do not know if another sample of citizens would have adopted similar opinions after the process and if the information phase would consistently prove to have the most significant effect on opinions [23,71]. Citizens' juries are potentially more affected by this issue than other types of mini-public, since they do not comprise scientifically comparable samples [24]. The question of how reliable mini-publics' outcomes are is important, as some scholars suggest that the opinions of mini-public participants should act as trusted proxies to guide broader public opinion and policy-making [9]. Whether the opinions of mini-public participants are consistently compatible with norms of deliberation should be a crucial consideration on whether they should be trusted proxies. Consequently, the study presented here considers if, how and when participants changed their views in three citizens' juries, in substantively different contextual frames, held contemporaneously on the same issue. Such an approach has been hailed as essential: 'If we want to find out more about how deliberation can best be institutionalised, we need cases where institutional characteristics form the independent variable and where other variables that affect outcomes of interaction are as constant as possible' [14] (p. 397). Goodin and Niemeyer [35] issued one survey between the information and deliberation phase of their jury, and so were unable to trace the influence of the reflection phase on an opinion that occurs in-between. We issued four surveys to overcome this limitation. We turn now to a full consideration of these cases and methods.

\section{Materials and Methods}

The research was designed as a natural experiment, whereby the project held three standardised citizens' juries in different locations in Scotland, selected according to their exposure to windfarm developments at the time (Table 1). Essentially, one location (Coldstream) acted as the control group, since no windfarms existed or were planned, while the others either had existing windfarms in the locality (Aberfeldy) or they were under consideration (Helensburgh). The only other variation between the groups was the participants themselves, who were selected to reflect the socio-demographic diversity present across Scotland and exhibiting varying attitudes to wind energy. There was no opportunity to randomise individuals to the different localities in order to implement a pure experiment. There was also an unavoidable change of two of the five witnesses who provided 
information in Coldstream. In all other respects, the conditions were kept as constant as possible.

Table 1. Three Scottish citizens' juries on windfarms $(n=47)$.

\begin{tabular}{cccccc}
\hline $\begin{array}{c}\text { Jury } \\
\text { Number }\end{array}$ & $\begin{array}{c}\text { Town (Local } \\
\text { Authority) }\end{array}$ & Dates & $\mathbf{N}$ & $\begin{array}{c}\text { Town } \\
\text { Population }\end{array}$ & Windfarms Status (in 2013) \\
\hline 1 & $\begin{array}{c}\text { Coldstream } \\
\text { (Scottish Borders) }\end{array}$ & $\begin{array}{c}\text { Day 1: 26 October 2013 } \\
\text { Day 2: 16 November 2013 }\end{array}$ & $\begin{array}{c}15 \\
7 \text { male, } 8 \text { female }\end{array}$ & 1813 & $\begin{array}{c}\text { No existing or proposed } \\
\text { windfarms nearby }\end{array}$ \\
\hline 2 & $\begin{array}{c}\text { Helensburgh } \\
\text { (Argyll and Bute) }\end{array}$ & $\begin{array}{c}\text { Day 1: 9 November 2013 } \\
\text { Day 2: 23 November 2013 }\end{array}$ & $\begin{array}{c}10 \text { male, } 4 \text { female } \\
\text { (14) }\end{array}$ & $\begin{array}{c}14,626 \\
\text { Early stages of proposal; } \\
\text { small windfarm 2 km away }\end{array}$ \\
\hline 3 & $\begin{array}{c}\text { Aberfeldy (Perth } \\
\text { and Kinross) }\end{array}$ & $\begin{array}{c}\text { Day 1: 18 January 2014 } \\
\text { Day 2: 1 February 2014 }\end{array}$ & 6 male, 12 female & 1895 & $\begin{array}{c}\text { Large operating windfarm; } \\
\text { within 10 km }\end{array}$ \\
\hline
\end{tabular}

The research project was overseen by a formal Stewarding Board, including advocates and opponents of windfarms, and had two broad aims, to contribute to: (1) substantive understanding of public attitudes to onshore windfarm development, and (2) methodological understanding of mini-publics and how they might be used. This paper focuses on aspects of the latter aim. In order to develop analytical purchase on this second aim, we developed two sets of hypotheses $(\mathrm{H})$, based on previous research, that we wished to evaluate in relation to the phase ( $\mathrm{H} 1$ and $\mathrm{H} 2)$ and context $(\mathrm{H} 3$ to $\mathrm{H} 5)$ of the citizens' juries, respectively. These are presented schematically for ease of reference and overview, but they follow from the insights gleaned from the earlier sections, with brief rationales provided after each one.

Hypothesis 1 (H1). Greater opinion change is expected in the information phase.

This is likely to be the result of witness argumentation, as well as general information received on Day 1 [52].

Hypothesis 2 (H2). The facilitated deliberation phase is likely to reveal greater change at the individual level rather than in aggregate opinions, through a more nuanced and open-minded appreciation of opposing arguments.

While facilitated deliberation is expected to minimise enclave polarisation [42,72], opinion crystallisation, rather than change, may occur where there is little diversity in starting positions [73].

Hypothesis 3 (H3). Lack of local relevance of windfarms, either now or in the immediate future, is likely to lead to a relatively neutral set of opinions.

This indicates that we would expect Coldstream to be relatively indifferent in their attitudes compared to the other juries, since there are no local consequences [31].

Hypothesis $4 \mathbf{~ ( H 4 ) . ~ U n l e s s ~ t h e r e ~ a r e ~ p e r c e i v e d ~ d e t r i m e n t a l ~ e f f e c t s , ~ f a m i l i a r i t y ~ w i t h ~ w i n d f a r m s ~ i s ~}$ likely to lead to acceptance of the status quo, leading to:

Hypothesis 4a (H4a). The most positive attitudes.

Previous research has made this connection $[74,75]$.

Hypothesis $4 \mathbf{b}(\mathbf{H} 4 \mathbf{b})$. Smaller changes in opinions.

This would suggest that, in the absence of evidence of detriment, Aberfeldy is likely to show the most positive attitudes to windfarms and the least change in their opinions during the process compared to Coldstream or Helensburgh [76]. 
Hypothesis 5 (H5). Anticipation of change without public involvement, when the outcome is unfamiliar or unexpected, creates uncertainty, leading to resistance and negative opinions of that change.

It would be expected that the greatest negative opinion would be seen in Helensburgh (planned windfarm), where jurors did not raise the principle of public involvement, unlike the other juries. Existing research has shown the importance of community participation on acceptance, especially through information sharing [77], rather than NIMBYism [76]. Differences between localities are expected to occur irrespective of variations in group composition relating to socio-demography [55] but may be affected by different starting attitudes [73].

\subsection{Sample}

Each jury comprised between 14 and 18 participants (Table 1), selected to represent a cross-section of Scottish citizens by gender, age, and income (Table 2). The group also represented a mixture of educational attainment, working status, involvement in civic activities, such as volunteering or activism, and a range of attitudes towards the environment and wind farms. The initial sample was 49 jurors, but two female participants (Coldstream and Helensburgh) dropped out during the process due to ill health or relocation, leaving 47.

Table 2. Participant demography (aggregate of the three citizens' juries) $(n=47)$.

\begin{tabular}{|c|c|c|c|}
\hline Demographic Measure & Target (\%) & Actual (\%) & Actual (n) \\
\hline \multicolumn{4}{|l|}{ Gender } \\
\hline Male & 50 & 49 & 23 \\
\hline Female & 50 & 51 & 24 \\
\hline \multicolumn{4}{|l|}{ Age } \\
\hline $18-24$ & 20 & 19 & 9 \\
\hline $25-54$ & 50 & 53 & 25 \\
\hline $55+$ & 30 & 28 & 13 \\
\hline \multicolumn{4}{|l|}{ Working status } \\
\hline Full time & \multirow{3}{*}{ Mix } & 45 & 21 \\
\hline Part time & & 9 & 4 \\
\hline Not working & & 47 & 22 \\
\hline \multicolumn{4}{|l|}{ Education } \\
\hline School & \multirow{4}{*}{ Mix } & 11 & 5 \\
\hline Further education & & 21 & 10 \\
\hline Higher education & & 47 & 22 \\
\hline $\begin{array}{c}\text { Other (inc. professional/trade } \\
\text { qualifications) }\end{array}$ & & 21 & 10 \\
\hline \multicolumn{4}{|l|}{ Income (6 non-responses) } \\
\hline under GBP 15,999 per year & $>40$ & 34 & 14 \\
\hline GBP 16,000 GBP 31,199 & $>20$ & 37 & 15 \\
\hline GBP 31,200 to GBP 51,999 & $>10$ & 20 & 8 \\
\hline GBP 52,000 or above & $>5$ & 10 & 4 \\
\hline
\end{tabular}


Table 2. Cont.

\begin{tabular}{|c|c|c|c|}
\hline Demographic Measure & Target $(\%)$ & Actual (\%) & Actual (n) \\
\hline \multicolumn{4}{|l|}{ Civic activities } \\
\hline Have taken part in one or more activities & \multirow{2}{*}{ Mix } & 49 & 23 \\
\hline Have not taken part & & 51 & 24 \\
\hline \multicolumn{4}{|l|}{ Attitudes towards windfarms in Scotland } \\
\hline Should be more & \multirow{3}{*}{ Mix } & 45 & 21 \\
\hline Should be fewer & & 24 & 11 \\
\hline Current level about right & & 31 & 15 \\
\hline \multicolumn{4}{|l|}{$\begin{array}{l}\text { Attitudes towards the environment } \\
\qquad \text { (4 non-responses) }\end{array}$} \\
\hline Very/fairly interested & \multirow{3}{*}{ Mix } & 88 & 38 \\
\hline Neither interested nor uninterested & & 5 & 2 \\
\hline Not very/not at all interested & & 7 & 3 \\
\hline
\end{tabular}

Participants were recruited face-to-face by a market research company according to a pre-agreed specification. The jury topic remained unknown to the participants prior to the event to minimise the self-selection of an already engaged minority, so the project was vaguely described to prospective participants as 'public conversations about environmental issues'. A question in the recruitment process allowed the selection of participants with a range of interests in wind energy, without revealing at this stage that the discussions were going to focus on onshore windfarms. Recruiters were instructed to assure participants that knowledge or interest in environmental issues did not affect eligibility. If the topic was completely unknown, people may have been reticent to sign up.

Each jury was held over two full days (Saturdays), either 2 or 3 weeks apart, for which jurors were compensated for their participation (GBP 70 for day 1; GBP 100 for day 2). The process was designed and facilitated by two engagement practitioners, whose approach is outlined in Escobar et al. [78]. At the start participants were presented with the overall task for the citizens' jury: "There are strong views on windfarms in Scotland, with some people being strongly opposed, others being strongly in favour and a range of opinions in between. What should be the key principles for deciding about windfarm development in Scotland, and why?"

\subsection{Content of the Citizens' Juries}

There were three evidence sessions on Day 1:

I. Energy and Climate Change: One academic witness, who sought to present an impartial overview.

II. Wind Energy: Two witnesses, one presenting the argument 'for' and the other 'against' wind power.

III. Windfarms: Two witnesses (different from those in session two), one presenting the argument 'for' and the other 'against' onshore windfarms.

For each, the jury heard brief presentations from the witness(es) followed by a longer session for scrutiny, where the jurors first worked in groups to prioritise key questions and then interrogated the witnesses in plenary. The witnesses were drawn from universities (3), NGOs (2), and trade bodies (2).

Should the jurors wish to learn more between the two days, each participant was provided with a user-friendly Handbook (https: / / www.climatexchange.org.uk/media/14 42/citizens_juries_handbook.pdf (accessed on 26 August 2021)), which presented background information about climate change and energy, and links to resources for further information in various formats. The Handbook was prepared by an independent group under the oversight of the Stewarding Board. After Day 1, the witnesses were given a list 
of questions that were not addressed in the plenary, due to time constraints. Their written answers were circulated to the jurors approximately a week before Day 2.

On Day 2, the jurors set the agenda by agreeing on key themes to structure the deliberations, which eventually led to the group 'verdict'; a series of prioritised statements that expressed their principles for windfarm development and summed up the various group opinions. The same process was adopted for all three juries with respect to the structure, duration, topic, facilitators, and engagement with witnesses.

\subsection{Data Construction}

The project entailed a parallel mixed methods research design [79], comprising six data sources, including questionnaires conducted individually at four time points and several interviews and observations. This paper focuses largely on relevant results from the questionnaires, supplemented by observations of ethnographers and evaluators, to understand if, how and when citizens' opinions changed during the jury process.

Jurors were asked to complete a series of highly structured questionnaires throughout the process, incorporating mainly closed response options. Several questions were repeated throughout the process, enabling opinions to be tracked. The four questionnaires were administered to record participants' opinions and beliefs during the process as follows:
a. QA1, at the start of Day 1, as a baseline measure
b. QA2, at the end of Day 1, following the information phase (i.e., the formal evidence- giving phase)
c. QA3, at the start of Day 2, following the reflection phase (i.e., following a 2 or 3 week break between jury days)
d. QA4, at the end of Day 2, following the deliberation phase.

Therefore, we are able to assess the extent of opinion change in the reflection phase, unlike in the Goodin and Niemeyer [35] study.

\subsection{Data Analysis}

Data from the four survey questionnaires are used in the following analyses. Three scaled variables are created to reflect citizens' underlying opinions on wind power and energy policy, windfarms in the locality, and windfarm planning, respectively. Each scale is an additive index based on the strength of agreement/disagreement with a series of statements related to each of the three topics, for which scale reliability is calculated using Cronbach's alpha (Table 3). Each question was scored -2 (strongly disagree), -1 (disagree), 0 (neither agree nor disagree), +1 (agree), +2 (strongly agree), based on level of agreement with each statement. Missing values were replaced by the median response to the given question in the survey wave for that jury location.

Table 3. Scaled variable question composition and reliability scores.

\begin{tabular}{lc}
\hline \multicolumn{1}{c}{ Scale } & $\begin{array}{c}\text { Coding } \\
\text { Reversed (X) }\end{array}$ \\
\hline 1: Wind Power and Energy Policy & $X$ \\
\hline It is important for Scotland to develop its wind energy resources & \\
I think Scotland should invest in other renewable electricity sources rather & \\
than wind power & \\
Wind energy development is important for combatting climate change & \\
Wind energy development is economically important for Scotland \\
For wind energy, the positives outweigh the negatives \\
Windfarm developments offer the prospect of future jobs in Scotland \\
Cronbach's alpha: 0.9216
\end{tabular}


Table 3. Cont.

\begin{tabular}{|c|c|}
\hline Scale & $\begin{array}{c}\text { Coding } \\
\text { Reversed (X) }\end{array}$ \\
\hline \multicolumn{2}{|l|}{ 2: Windfarms in the Locality } \\
\hline \\
\hline \multicolumn{2}{|l|}{$\begin{array}{l}\text { I would like it if this area produced electricity from wind power, if the } \\
\text { electricity was for local use }\end{array}$} \\
\hline $\begin{array}{l}\text { I would prefer to see electricity from wind power produced somewhere } \\
\text { other than this area }\end{array}$ & $x$ \\
\hline Windfarm developments decrease the value (the price) of houses nearby & $X$ \\
\hline $\begin{array}{l}\text { The financial rewards from windfarms benefit the energy companies rather } \\
\text { than the local community }\end{array}$ & $X$ \\
\hline \multicolumn{2}{|l|}{$\begin{array}{l}\text { Overall, communities located close to windfarms benefit from the } \\
\text { development }\end{array}$} \\
\hline \multicolumn{2}{|l|}{ Windfarms would not change my relationship with the countryside } \\
\hline \multicolumn{2}{|l|}{ Cronbach's alpha: 0.7842} \\
\hline \multicolumn{2}{|l|}{ 3: Windfarm Planning } \\
\hline \multicolumn{2}{|l|}{ I support the development of onshore windfarms in appropriate locations } \\
\hline Windfarms pose greater threat to the local environment than climate change & $X$ \\
\hline \multicolumn{2}{|l|}{$\begin{array}{l}\text { Windfarms are planned and designed to minimise the potential } \\
\text { environmental damage }\end{array}$} \\
\hline \multicolumn{2}{|l|}{$\begin{array}{l}\text { Windfarms are planned and designed to minimise the potential disruption to } \\
\text { people living nearby }\end{array}$} \\
\hline \multicolumn{2}{|l|}{$\begin{array}{l}\text { The rules about wind farm plans minimise the noise and visual appearance } \\
\text { of wind farms }\end{array}$} \\
\hline Windfarms are harmful to the health of people living nearby & $X$ \\
\hline Cronbach's alpha: 0.8663 & \\
\hline
\end{tabular}

Comparisons are made between jurors' opinions following each phase of the deliberative process using two different approaches. The first treats each jury as a separate sample to compare average opinion changes within juries, to provide contextual comparisons over the jury process. We use paired sample $t$-tests and Wilcoxon sign-tests to compare changes in the mean and median values, respectively. The second combines the three juries into one general sample (due to the similar structure and timing across all juries), to increase the statistical power in our analyses in understanding if, how, and when changes take place overall. A four-wave Generalised Least Squares (GLS) model with random effects [80] was used to investigate the relationship between each jury phase and individuals' opinions on each of the three scales, with standard errors clustered by location. All statistical analysis was conducted using Stata, v14.2.

\section{Results}

For all three scales (Table 4), the starting opinions (QA1) were most positive in Aberfeldy, the locality with a windfarm, and least positive in Helensburgh, where a windfarm was being considered. We discuss statistically significant changes in each scale for each phase in turn, though a similar pattern is observed across all three scales.

At the beginning of Day 1, individuals held a positive opinion of wind power and energy policy, particularly in Aberfeldy and Coldstream, while Helensburgh bordered on neutral. However, opinions in Coldstream declined notably during the information phase, with no significant change thereafter, ending fairly neutral. In Aberfeldy, a small (not statistically significant) opinion decline occurred during the first day (information phase) and between the first and the second day (reflection phase), but with no noticeable effect during the deliberation phase, still concluding positively. Helensburgh, however, revealed a significant decline, particularly during the information phase (which shows the 
most dramatic opinion shift observed in all scales), but also the deliberation phase, leaving them ultimately much more negative than the other juries in absolute terms.

Table 4. Jurors' opinion changes over two days for three scaled variables.

\begin{tabular}{|c|c|c|c|c|c|c|c|}
\hline Questionnaire & Mean & Median & $\begin{array}{l}\text { Standard } \\
\text { Deviation }\end{array}$ & Min & Max & $\begin{array}{c}\text { Phase Change } \\
\text { in Mean }\end{array}$ & $\begin{array}{c}\text { Phase Change } \\
\text { in Median }\end{array}$ \\
\hline \multicolumn{8}{|c|}{ 1. Wind Power and Energy Policy ( -12 most negative; 0 neutral; 12 most positive) } \\
\hline \multicolumn{8}{|c|}{ All jurors $(n=47)$} \\
\hline QA1 & 2.64 & 4 & 5.89 & -12 & 11 & & \\
\hline QA2 & -0.47 & 1 & 6.46 & -12 & 9 & $-3.11^{* * *}$ & $-3.00 * * *$ \\
\hline QA3 & -0.49 & 1 & 6.81 & -12 & 11 & -0.02 & 0 \\
\hline QA4 & -1.30 & 0 & 7.02 & -12 & 10 & $-0.81^{*}$ & -1 \\
\hline \multicolumn{8}{|c|}{ Coldstream $(n=15)$} \\
\hline QA1 & 2.73 & 4 & 5.75 & -10 & 10 & & \\
\hline QA2 & 0.80 & 1 & 5.19 & -12 & 9 & $-1.93^{* * *}$ & $-3.00^{* * *}$ \\
\hline QA3 & 1.87 & 2 & 6.22 & -12 & 10 & 1.07 & 1 \\
\hline QA4 & 0.87 & 1 & 4.75 & -12 & 9 & -1 & -1 \\
\hline \multicolumn{8}{|c|}{ Helensburgh $(\mathrm{n}=14)$} \\
\hline QA1 & 0.43 & -1 & 7.52 & -12 & 11 & & \\
\hline QA2 & -6.57 & -7 & 4.15 & -12 & 2 & $-7.00^{* * *}$ & $-6.00^{* *}$ \\
\hline QA3 & -6.36 & -7 & 5.79 & -12 & 11 & 0.21 & 0 \\
\hline QA4 & -8.21 & -11 & 5.55 & -12 & 8 & $-1.85^{* *}$ & -4 \\
\hline \multicolumn{8}{|c|}{ Aberfeldy $(\mathrm{n}=18)$} \\
\hline QA1 & 4.28 & 4 & 4.06 & -7 & 11 & & \\
\hline QA2 & 3.22 & 4 & 5.59 & -12 & 9 & -1.06 & 0 \\
\hline QA3 & 2.11 & 3 & 5.26 & -9 & 9 & $-1.11 *$ & -1 \\
\hline QA4 & 2.28 & 4 & 5.86 & -11 & 10 & 0.17 & 1 \\
\hline \multicolumn{8}{|c|}{ 2. Windfarms in the locality ( -14 most negative; 0 neutral; 14 most positive) } \\
\hline \multicolumn{8}{|c|}{ All jurors $(\mathrm{n}=47)$} \\
\hline QA1 & 0.17 & 1 & 5.55 & -13 & 9 & & \\
\hline QA2 & -2.19 & -1 & 5.05 & -10 & 8 & $-2.36^{* * *}$ & $-2.00 * * *$ \\
\hline QA3 & -2.00 & -1 & 5.31 & -11 & 9 & 0.19 & 0 \\
\hline QA4 & -2.53 & -2 & 5.16 & -14 & 8 & -0.53 & -1 \\
\hline \multicolumn{8}{|c|}{ Coldstream $(\mathrm{n}=15)$} \\
\hline QA1 & 0.07 & 1 & 4.53 & -13 & 6 & & \\
\hline QA2 & -0.33 & 1 & 3.85 & -10 & 7 & -0.4 & 0 \\
\hline QA3 & 0.20 & 0 & 3.47 & -7 & 6 & 0.53 & -1 \\
\hline QA4 & -0.67 & 0 & 4.78 & -14 & 7 & -0.87 & 0 \\
\hline \multicolumn{8}{|c|}{ Helensburgh $(\mathrm{n}=14)$} \\
\hline QA1 & -1.29 & -2 & 5.84 & -13 & 6 & & \\
\hline QA2 & -6.93 & -7 & 2.81 & -10 & -1 & $-5.64^{* * *}$ & $-5.00 * *$ \\
\hline QA3 & -6.93 & -7 & 3.52 & -10 & 2 & 0 & 0 \\
\hline QA4 & -5.93 & -7 & 4.46 & -11 & 3 & 1 & 0 \\
\hline \multicolumn{8}{|c|}{ Aberfeldy $(n=18)$} \\
\hline QA1 & 1.39 & 3 & 6.08 & -12 & 9 & & \\
\hline QA2 & -0.06 & 0 & 4.93 & -10 & 8 & -1.45 & -3 \\
\hline QA3 & 0.00 & -1 & 5.32 & -11 & 9 & 0.06 & -1 \\
\hline QA4 & -1.44 & -2 & 4.93 & -10 & 8 & -1.44 * & -1 \\
\hline
\end{tabular}


Table 4. Cont.

\begin{tabular}{|c|c|c|c|c|c|c|c|}
\hline Questionnaire & Mean & Median & $\begin{array}{l}\text { Standard } \\
\text { Deviation }\end{array}$ & Min & $\operatorname{Max}$ & $\begin{array}{l}\text { Phase Change } \\
\text { in Mean }\end{array}$ & $\begin{array}{c}\text { Phase Change } \\
\text { in Median }\end{array}$ \\
\hline \multicolumn{8}{|c|}{ 3. Windfarm Planning ( -14 most negative; 0 neutral; 14 most positive) } \\
\hline \multicolumn{8}{|c|}{ All jurors $(n=47)$} \\
\hline QA1 & 3.85 & 6 & 6.26 & -14 & 14 & & \\
\hline QA2 & 1.62 & 2 & 6.51 & -14 & 14 & $-2.23^{* * *}$ & $-4.00^{* * *}$ \\
\hline QA3 & 1.40 & 2 & 6.84 & -12 & 14 & -0.22 & $0.00 *$ \\
\hline QA4 & 0.91 & 3 & 7.12 & -14 & 14 & -0.49 & 1 \\
\hline \multicolumn{8}{|c|}{ Coldstream $(\mathrm{n}=15)$} \\
\hline QA1 & 4.40 & 6 & 6.34 & -14 & 10 & & \\
\hline QA2 & 2.73 & 4 & 4.35 & -5 & 10 & -1.67 & $-2.00 *$ \\
\hline QA3 & 3.80 & 5 & 5.20 & -6 & 14 & 1.07 & 1 \\
\hline QA4 & 2.87 & 3 & 5.82 & -8 & 14 & -0.93 & -2 \\
\hline \multicolumn{8}{|c|}{ Helensburgh $(\mathrm{n}=14)$} \\
\hline QA1 & 1.36 & 1 & 6.86 & -13 & 14 & & \\
\hline QA2 & -3.50 & -6 & 6.35 & -14 & 10 & $-4.86^{* * *}$ & $-7.00 *$ \\
\hline QA3 & -5.36 & -6 & 5.11 & -12 & 6 & $-1.86^{* *}$ & $0.00 * *$ \\
\hline QA4 & -5.71 & -7 & 6.06 & -14 & 5 & -0.35 & -1 \\
\hline \multicolumn{8}{|c|}{ Aberfeldy $(n=18)$} \\
\hline QA1 & 5.33 & 6 & 5.41 & -11 & 14 & & \\
\hline QA2 & 4.67 & 4 & 5.99 & -11 & 14 & -0.66 & -2 \\
\hline QA3 & 4.67 & 5 & 5.50 & -7 & 13 & 0 & 1 \\
\hline QA4 & 4.44 & 5 & 5.35 & -10 & 13 & -0.23 & 0 \\
\hline
\end{tabular}

${ }^{*} p<0.10 ;{ }^{* *} p<0.05 ;{ }^{* * *} p<0.01$. Key: QA1: Start of Day 1, QA2: End of Day 1, QA3: Start of Day 2, QA4: End of Day 2.

Regarding the second scale, windfarms in the locality, jurors in Aberfeldy (located close to a large windfarm) showed the most positive opinions at the start but became more negative during deliberation, ending more negative than jurors in Coldstream (where there were no windfarms proposed at the time), which had remained relatively neutral throughout. Helensburgh, where at the time of the study a prospective windfarm development was being proposed, started negatively and then declined further during the information phase.

The third scale, concerning windfarm planning, showed strongly positive support in Coldstream and Aberfeldy at the beginning, with a more neutral stance in Helensburgh. Once again, from a moderately positive position at the start, a statistically significant decline was seen in Helensburgh during the information and reflection phases, while a relatively small decline was seen in Coldstream during the information phase. Opinions in Aberfeldy remained high throughout the phases.

If we treat the three juries as one sample, we consistently see statistically significant declines in opinion in all scales following the information phase, in both the means and the medians, influenced by the strong effect in Helensburgh. Smaller declines are evident in different localities during the reflection and deliberation phases. In general, there was a high level of stability in the period between the two jury days. Nonetheless, there was a fair degree of opinion diversity at the individual level at each stage, as shown by the relatively large standard deviations.

The results above indicate that jurors do exhibit changes in opinion during the process and, moreover, these occur in different phases and on different topics to different degrees in the three jury locations. The random-effects GLS regression model in Table 5, with standard errors clustered by location, looks at the level of opinion at each phase of the process relative to the start for all jurors $(n=47)$. While the models were run with the inclusion of socio-demographic traits, including age, gender, and education level, none of 
these attributes were found to be statistically meaningful in explaining levels of opinion and were therefore omitted here to create a more parsimonious model.

Table 5. Regression model coefficients for opinion changes by phase for each scale.

\begin{tabular}{|c|c|c|c|c|c|c|}
\hline & \multicolumn{2}{|c|}{ Wind Power and Energy Policy } & \multicolumn{2}{|c|}{ Windfarms in Locality } & \multicolumn{2}{|c|}{ Windfarm Planning } \\
\hline & \multicolumn{2}{|c|}{ Coefficient } & \multicolumn{2}{|c|}{ Coefficient } & \multicolumn{2}{|c|}{ Coefficient } \\
\hline & (s.e.) & $p$-Value & (s.e.) & $p$-Value & (s.e.) & $p$-Value \\
\hline $\begin{array}{l}\text { Constant } \\
\text { (OA1) }\end{array}$ & 2.638 & 0.019 & 0.170 & 0.829 & 3.851 & 0.001 \\
\hline & $(1.124)$ & & $(0.788)$ & & $(1.174)$ & \\
\hline QA2 & $\begin{array}{l}-3.106 \\
(1.790)\end{array}$ & 0.083 & $\begin{array}{l}-2.362 \\
(1.497)\end{array}$ & 0.115 & $\begin{array}{l}-2.234 \\
(1.237)\end{array}$ & 0.071 \\
\hline QA3 & $\begin{array}{l}-3.128 \\
(1.677)\end{array}$ & 0.062 & $\begin{array}{l}-2.170 \\
(1.610)\end{array}$ & 0.178 & $\begin{array}{l}-2.447 \\
(1.924)\end{array}$ & 0.203 \\
\hline QA4 & $\begin{array}{l}-3.936 \\
(2.121)\end{array}$ & 0.064 & $\begin{array}{l}-2.809 \\
(1.156)\end{array}$ & 0.015 & $\begin{array}{l}-2.936 \\
(1.886)\end{array}$ & 0.119 \\
\hline $\mathrm{n}$ & \multicolumn{2}{|c|}{188} & \multicolumn{2}{|c|}{188} & \multicolumn{2}{|c|}{188} \\
\hline $\mathrm{R}^{2}$ & \multicolumn{2}{|c|}{0.0511} & \multicolumn{2}{|c|}{0.0418} & \multicolumn{2}{|c|}{0.0282} \\
\hline
\end{tabular}

Table 5 reveals the varied mean starting opinion levels for each scale, with 'wind power and energy policy', and 'windfarm planning' initially positive, while 'windfarm locality' showed a relatively neutral view. Following the information phase on Day 1 , the initially positive scales exhibited negative opinion shifts that were marginally statistically significant. During the period between the jury days, when participants could reflect on the first day, opinions hardly changed.

After the second day, when participants had the opportunity to deliberate on the topic, views on the scales 'wind power and energy policy', and 'windfarm locality' are statistically more negative than the start of the process, unlike 'windfarm planning', despite all three scale coefficients indicating lower mean opinion levels. The inability to obtain statistically significant findings could be an artefact of small sample sizes, reflecting the nature of the project.

\section{Discussion}

We find that during a citizens' jury, the information phase most influences jurors' opinions, rather than the reflection and deliberation phases. This is in agreement with other studies [35,62,63], and supports our first hypothesis (H1).

Across all three scales, we repeatedly observe statistically meaningful changes across the information phase. Given the likelihood of being more informed in Aberfeldy, due to the existence of a windfarm locally, jurors show less change than in the other localities in relation to wind power/energy policy and windfarm planning, although not windfarms in the locality.

There is evidence of a smaller change in aggregate opinions in the deliberative phase, compared to the information phase, but higher variation in individual opinions within each phase as measured by the standard deviation. Jurors reported higher self-assessed and retained knowledge after Day 2, despite little formal information exchange in the deliberation phase, indicating support for the second hypothesis (H2).

Most jurors considered climate change to be an important issue, although some Coldstream and Aberfeldy participants did not hold this view. However, the Helensburgh jury was less in favour of renewables, initially arguing for natural gas (fossil fuel) in their top five energy sources, later replaced by nuclear energy. Given the relatively negative opinion throughout the process on all three scales in Helensburgh, a jury that commented on its relative unanimity of attitudes, it does suggest that there has been a crystallisation of opinions by the conclusion. The relatively large standard deviation in the deliberation 
phase, coupled with relatively less aggregate change, does show support for the second hypothesis.

The relatively neutral or middle position throughout the process found in Coldstream, where no windfarms existed or were planned, indicates strong support for the third hypothesis (H3) across all scales. It is interesting that, while these jurors' attitudes became more negative during the information phase in relation to wind power/energy policy and windfarm planning, there was little statistical change subsequently on any scale. Their views are more likely to be hypothetical than Aberfeldy, which may be particularly apposite concerning local impact, given that their attitudes may be inconsequential.

There is clear evidence for Aberfeldy having the most positive opinions throughout the process compared to the other localities, thus supporting hypothesis $\mathrm{H} 4 \mathrm{a}$, except after deliberation about windfarms in the locality. This jury does show the least change in opinions in relation to windfarm planning, but about the same as Coldstream in 'wind power and energy policy' and more than Coldstream in relation to 'windfarms in the locality'. We have already noted that there may have been some local experiential concerns about developments in Aberfeldy, which had a particular impact on this scale. It is worthy of note that this locality is the only one not to have had statistically significant changes in opinion after the information phase. Thus, we find partial support for the second part of the fourth hypothesis $(\mathrm{H} 4 \mathrm{~b})$, conditioned by non-hypothetical considerations.

There is very clear evidence in support of the fifth hypothesis (H5). The unfamiliarity or unexpected change in the local area may be the likely cause of Helensburgh's jury exhibiting the most negative opinions on all three scales, both in relative and absolute measure across the process. Although there was some imbalance in the gender composition of this jury, it did not appear to show a consistent pattern. However, the imbalance of views in this jury, unlike the others, with a clear dominance of a more negative view of wind power before the start of the process is likely to explain the ensuing results. Only one juror revealed a constantly positive position across the scales.

At first sight, our results may appear rather odd, given that deliberative theory argues that opinion transformation is a result of collective discussion, argument, and public reasoning, rather than simply more information [10-13,29]. However, as discussed earlier, Goodin [36,37] and Goodin and Niemeyer [35] emphasise that it is not necessarily deliberation, per se, that causes opinion reflection and opinion change, but a combination of a focus of attention on the issue, the acquisition of information about it, and a process of internal reflection, possibly induced by having to deliberate the issues later in the process and the need to find a publicly defensible position. In other words, the prospect of having to engage in group deliberation, justifying one's opinions, and articulating a public position, provides a strong incentive for jurors to take in and reflect on the evidence shared during the information phase. Goodin and Niemeyer [35] believe that the pre-discursive phase will invariably have greater salience than the deliberation phase, by changing the way that jurors relate to an issue.

We think there is great value in the replication of the Goodin and Niemeyer findings to both the internal and external validity of their project and ours [81]. This is especially the case as, methodologically, we move beyond their study [82] to look at consistency in opinion change in several standardised citizens' juries and introduced an additional survey instrument to enable us to account for the reflection period. This enabled us to consider other contextual factors that might have a bearing on opinion change in citizens' juries. In order to understand the factors that influence participants' opinions and how they might change, we have considered such factors as the change in knowledge throughout the jury process, proximity to windfarms (as measured by the different jury locations), the strength of initial opinion on the topic, and socio-demographic characteristics. It is possible that the witnesses, representing organisations with presumed authority, had an inordinate effect on some jurors, especially if their own knowledge on the issue was limited. This was the second most important reason for opinion change in the Goodin and Niemeyer study [35]. Our analytical models explored the effects of socio-demographic variables 
(i.e., age, gender, and education), but we find very little correlation with the opinion changes observed. As with Goodin and Niemeyer [35], we also conclude that our results are not epiphenomenal. Although the information phase was the first phase in each of the three juries we analysed, we look to evidence from deliberative polls which follow a discussion-information-discussion format, but still found the information phase most crucial. In addition, unlike the citizens' jury that Goodin and Niemeyer [35] considered, in the three Scottish citizens' juries the information and deliberation phases each had the same duration.

Most participants in each jury began the process slightly in favour of the current energy policy and windfarm development in Scotland. However, it seems that exposure to the complexity of the arguments during the information phase, which were sometimes presented as a political debate, led to a more considered, nuanced, and sometimes sceptical response. For example, the development principles generated by the juries feature support to strengthen community benefits, local economic impact, and even public ownership as a corrective to current profit-making by private landowners and developers of wind farms. We also found from the ethnographer and observer fieldnotes, and survey questionnaire open questions, that witnesses can have a significant influence on the intra-process opinions of the citizen sample, whilst noting that the unavoidable change of two of them did not impact greatly on the changes across the juries. For the overwhelming majority of jurors, this was the first time they had been exposed to a task involving collective working with fellow citizens on policy issues. While the explicit reason for their involvement was to require them to deliberate on complex issues to arrive at a consensus on a set of principles, the incentive in the information phase was to listen, consider and weigh the evidence and values presented to them. Participants could reflect individually, or in groups, either while agreeing on questions to ask the witnesses, or via informal conversations in the interstices of the day; e.g., during tea/coffee breaks, over lunch, or in snatched asides to each other. In other words, learning as an activity is not a passive act, but is a response to various stimuli, both formal (information packs, witnesses) and informal (between jurors), that incorporates discursive and reflective processes. While the deliberative phase makes public the thoughts and discussions of jurors, it is erroneous to assume that the preceding phases are not incorporated as part of a cumulative and developmental process.

In QA4, although jurors reflected that they felt that they learnt the most about the topic on Day 1, the vast majority (88\%) sought additional information from the Handbook, the witnesses' feedback, friends and family, and the internet during the reflection phase. They also reported that the conversations in facilitated groups on Day 2 were useful for helping them to make up their mind. This was apparent in the statistically significant changes observed in the deliberation phase.

Nevertheless, it is clear that location is also an important factor in the findings about opinion change, with Helensburgh providing the starkest example of a negative change in opinions. Although jurors held similar views about renewable energy policy in all three localities, the opinions about wind energy, windfarms, and climate change were on average least supportive in the Helensburgh group from the start. The Helensburgh jury was not as diverse as the other juries. Women were under-represented (Table 1), and the recruitment company investigated these issues and found that the participants who did not attend were mostly those who expressed moderate support for wind energy in the hidden recruitment question. Thus, the jury had fewer advocates to express these perspectives during the group conversations. Deliberations were less rich and diverse in the individual sessions, and, at the end of Day 2, several jurors reflected how group discussions and agreements backed up their opinions. The one Helensburgh juror in favour of windfarms reported feeling like 'the only one' throughout the process.

Previous research on deliberation and opinion change has demonstrated the risk of 'enclave deliberation' as it can lead to opinion polarization $[18,83]$, although it might be more a case of crystallisation [73]. The lack of diversity in the initial opinions of the Helensburgh jurors led to the creation of such an enclave. However, we did not see 
opinions becoming unilaterally more extreme and polarised through the jury process; even in Helensburgh, despite considerable polarisation, opinions were fluid, with some participants becoming more supportive and others more opposed. This illustrates that jurors were engaging with both sides of the argument, rather than simply assimilating more information to back up views that they already held (confirmation bias). In short, opinion reflection was stimulated in all three juries. Nevertheless, this still demonstrates the importance of having a diversity of opinions in a mini-public beyond the witnesses and the particular challenges citizens' juries face here due to their small sample size.

It is difficult to be absolutely sure whether the possibility of a windfarm in the Helensburgh area influenced the jurors' attitudes, although the results are in line with the hypotheses. We do know that the plan had been controversial, especially given the rejection of another windfarm development nearby. However, it transpired that many jurors were unaware of the failed or future proposals, which might have raised their concerns in itself. Those jurors who lived in the other localities were either used to windfarms (Aberfeldy) or were likely to be aware of several moderate scale windfarms in their region (the Scottish Borders), even if not in their patch (Coldstream). Another factor that might have been important in the case of Helensburgh was the nearby location of a nuclear submarine base, a significant employer in the area. Unlike the other two localities, several of these jurors repeatedly suggested that nuclear power was a higher priority for energy production, a position also taken by one of the witnesses, which may explain the very negative mean for wind power in conclusion. This is in line with research that indicates that the local social, economic, political, and historical context of any particular place will shape attitudes towards any new development [84-86].

\section{Conclusions}

The strength of this study is in having three standardised juries in contexts that reflect different levels of development relating to the topic under discussion, yet dealing with the same questions, embedded within a longitudinal, and mixed methods design, resulting in rich data for analysing opinion change between each phase and in aggregate.

Our findings confirm the importance of the information phase in changing jurors' opinions, rather than the theoretically expected deliberative phase, or even the intermediary reflection phase. The provision of information causes a significant change in jurors' opinions, probably due to being relatively uninformed at the start, which is less pronounced in the rest of the deliberative process. Nevertheless, we believe the information phase had such an influence on opinions in part because the jurors knew they were going to collectively deliberate on these issues, which provided the incentive to gain information in order to develop and justify their positions. We tentatively conclude that our labelling of the phases, whilst ostensibly reflecting their purposes, actually may misrepresent what is occurring in the process. In a nutshell, there is deliberation in the information phase, and there is information in the deliberative phase. Therefore, we must be careful when ascribing too much influence to any single phase and focus more on understanding the cumulative and iterative effects of the mini-public process. Deliberative practice encompasses both learning and discussion interwoven throughout, albeit with activities that may encourage more of one or the other at different stages.

We conjecture that the information phase in these juries, through making the issues appear to be much more complex than first appreciated and, therefore, offering less clear solutions, led to jurors moderating their initial opinions and developing more nuanced and negative arguments. Reasoning may in fact take place in private or informally during the information phase, when these new challenges are made clear, rather than being delayed until the deliberation phase, when issues related to the psychological aspects of advocating and defending positions in public, such as confidence or saving face, become problematic. This might have been catalysed by the perceived requirement to become briefed prior to the deliberative phase. 
Importantly, we found that the information phase had the greatest influence on jury opinions in those localities without a windfarm, albeit unequally. This suggests that when different jurors discuss the same issue, under similar conditions, it is similar factors that determine the final opinions. This is important to supporting claims that mini-publics could be used to guide public opinion and policymaking, as it demonstrates that participants change their views for reasons desirable from a deliberative perspective, namely because they are more informed on the issue and because they need to develop an opinion on the issue that could be defended publicly. However, substantively different contextual frames can lead to inconsistent outcomes and how these factors can impact the outcomes of a citizens' jury. These findings are therefore important for our understanding of deliberative democracy and the institutionalisation of mini-publics. They demonstrate that citizens' juries should be opinion diverse, to avoid enclave deliberation and polarisation/crystallisation of views, and, if they are to be used for national policymaking, ideally they would include a mixture of different contexts to understand their impact.

Our comparative case study research adds further exemplars of the importance of pre-discursive work on opinion change and how particular features that maximize the contextual differences, in this case, the level of development of on-shore windfarms, while holding others constant (socio-demography, information, and witnesses), reveal how minipublics, such as citizens' juries, can affect outcomes. Albeit these findings were derived from an academic research project, they will be important knowledge for the use of citizens ${ }^{\prime}$ juries in an official policy process. As Flyvbjerg asserts [87], the richness of detail provided by case studies, however small in themselves, can contribute multiple exemplars to the cumulative development of generalised knowledge in a way that large samples may not.

Author Contributions: Conceptualization, O.E. and J.J.R.; data curation, O.E., J.J.R. and N.M.P.; formal analysis, N.M.P.; funding acquisition, O.E. and J.J.R.; investigation, A.G.H.T., O.E., J.J.R. and S.E.; methodology, A.G.H.T., O.E. and J.J.R.; project administration, O.E. and J.J.R.; resources, O.E. and J.J.R.; software, N.M.P.; supervision, O.E. and J.J.R.; validation, A.G.H.T.; writing-original draft, A.G.H.T., O.E., J.J.R. and S.E.; writing—review and editing, A.G.H.T., O.E., J.J.R., S.E. and N.M.P. All authors have read and agreed to the published version of the manuscript.

Funding: This research was supported as part of the ClimateXExchange programme, University of Edinburgh.

Institutional Review Board Statement: The study protocol was approved by the School of Social and Political Science Ethics Committee of the University of Edinburgh in 2012.

Informed Consent Statement: All research participants gave their written informed consent for inclusion before they participated in the study.

Data Availability Statement: The data and codebook for the analyses in this manuscript are available at https:/ / doi.org/10.7488/ds/3117 (accessed on 26 August 2021).

Acknowledgments: The research was sponsored by the Edinburgh Centre for Carbon Innovation and ClimateXChange, Scottish Government's Centre for Expertise on Climate Change. OE's contribution was supported by What Works Scotland (ESRC ES/M003922/1; and Scottish Government), and JR's contribution was supported by ClimateXChange and the University of Strathclyde. We would like to thank all the jury participants, witnesses and Stewarding Board members for their participation. We also appreciate the reviewers' constructive comments.

Conflicts of Interest: The authors declare no conflict of interest. The funders had no role in the design of the study; in the collection, analyses, or interpretation of data; in the writing of the manuscript, or in the decision to publish the results.

\section{References}

1. Galende-Sánchez, E.; Sorman, A.H. From consultation toward co-production in science and policy: A critical systematic review of participatory climate and energy initiatives. Energy Res. Soc. Sci. 2021, 73, 101907. [CrossRef]

2. United Nations. Transforming Our World: The 2030 Agenda for Sustainable Development; United Nations: New York, NY, USA, 2015.

3. Newig, J.; Challies, E.; Jager, N.W. Democratic innovation and environmental governance. In The Handbook of Democratic Innovation and Governance; Elstub, S., Escobar, O., Eds.; Edward Elgar: Cheltenham, UK, 2019; pp. 324-338. 
4. $\quad$ Elstub, S. Mini-publics: Issues and Cases. In Deliberative Democracy: Issues and Cases; Elstub, S., McLaverty, P., Eds.; Edinburgh University Press: Edinburgh, UK, 2014; pp. 166-188.

5. Strandberg, K.; Backström, K.; Berg, J.; Karv, T. Democratically Sustainable Local Development? The Outcomes of Mixed Deliberation on a Municipal Merger on Participants' Social Trust, Political Trust, and Political Efficacy. Sustainability 2021, 13, 7231. [CrossRef]

6. Kulha, K.; Leino, M.; Setälä, M.; Jäske, M.; Himmelroos, S. For the Sake of the Future: Can Democratic Deliberation Help Thinking and Caring about Future Generations? Sustainability 2021, 13, 5487. [CrossRef]

7. Habermas, J. Legitimation Crisis; Beacon Press: Boston, MA, USA, 1975.

8. Delli Carpini, M.X.; Cook, F.L.; Jacobs, L.R. Public Deliberations, Discursive Participation and Citizen Engagement: A Review of the Empirical Literature. Annu. Rev. Political Sci. 2004, 7, 315-344. [CrossRef]

9. MacKenzie, M.K.; Warren, M.E. Two Trust-based Uses of Minipublics in Democratic Systems. In Deliberative Systems: Deliberative Democracy at the Large Scale; Parkinson, J., Mansbridge, J., Eds.; Cambridge University Press: Cambridge, UK, $2012 ;$ pp. 95-124.

10. Chambers, S. Deliberative democratic theory. Annu. Rev. Political Sci. 2003, 6, 307-326. [CrossRef]

11. Elster, J. Introduction. In Deliberative Democracy; Elster, J., Ed.; Cambridge University Press: Cambridge, UK, $1998 ;$ pp. 1-19.

12. Page, B. Who Deliberates? Mass Media in Modern Democracy; Chicago University Press: Chicago, IL, USA, 1996.

13. Dryzek, J. Deliberative Democracy and Beyond: Liberals, Critics, Contestations; Oxford University Press: Oxford, UK, 2000.

14. Landwehr, C.; Holzinger, K. Institutional determinants of deliberative interaction. Eur. Political Sci. Rev. 2010, 2, 373-400. [CrossRef]

15. Druckman, J.N. Political Opinion Formation: Competition, Deliberation, and the (Ir)relevance of Framing Effects. Am. Political Sci. Rev. 2004, 98, 671-686. [CrossRef]

16. Mendelberg, T. The Deliberative Citizen: Theory and Evidence. In Political Decision-Making, Deliberation and Participation; Delli Carpini, M., Huddy, L., Shapiro, R., Eds.; Elsevier Science: San Diego, CA, USA, 2002; pp. 201-241.

17. Karpowitz, C.F.; Mendelberg, T. Groups and Deliberation. Swiss Political Sci. Rev. 2007, 13, 645-662. [CrossRef]

18. Sunstein, C.R. The Law of Group Polarization. J. Political Philos. 2002, 10, 175-196. [CrossRef]

19. Lupia, A. Deliberation Disconnected: What it Takes to Improve Civic Competence. Law Contemp. Probl. 2002, 65, 133-150. [CrossRef]

20. Baccaro, L.; Bächtiger, A.; Deville, M. Small Differences that Matter: The Impact of Discussion Modalities on Deliberative Outcomes. Br. J. Political Sci. 2016, 46, 551-566. [CrossRef]

21. Neblo, M.A. Change for the Better? Linking the Mechanisms of Deliberative Opinion Change to Normative Theory. Master's Thesis, University of Chicago, Chicago, IL, USA, 2000.

22. Neblo, M. Deliberative Democracy Between Theory and Practice; Cambridge University Press: Cambridge, UK, 2015.

23. Barabas, J. How deliberation affects policy opinions. Am. Political Sci. Rev. 2004, 98, 687-701. [CrossRef]

24. Fishkin, J.S. When the People Speak: Deliberative Democracy and Public Consultation; Oxford University Press: Oxford, UK, 2009.

25. Landwehr, C. Rational Choice, Deliberative Democracy, and Opinion Transformation. Stud. Soc. Political Thought 2005, 11, 40-68.

26. Rosenberg, S.W. Citizen Competence and the Psychology of Deliberation. In Deliberative Democracy: Issues and Cases; Elstub, S., McLaverty, P., Eds.; Edinburgh University Press: Edinburgh, UK, 2014; pp. 98-117.

27. Elstub, S. Towards a Deliberative and Associational Democracy; Edinburgh University Press: Edinburgh, UK, 2008.

28. Mackie, G. Does Democratic Deliberation Change Minds? Politics Philos. Econ. 2006, 5, 279-303. [CrossRef]

29. Cohen, J. Reflections on Deliberative Democracy. In Contemporary Debates in Political Philosophy; Chriatiano, T., Christman, J., Eds.; Wiley-Blackwell: Oxford, UK, 2009; pp. 247-264.

30. Manin, B. On Legitimacy and Political Deliberation. Political Theory 1987, 15, 338-368. [CrossRef]

31. Pincione, G.; Tesón, F. Rational Choice and Democratic Deliberation. A Theory of Discourse Failure; Cambridge University Press: Cambridge, UK, 2006.

32. Burchardt, T. Deliberative Research as a Tool to Make Value Judgements. Qual. Res. 2014, 14, 353-370. [CrossRef]

33. Gerber, M.; Bächtiger, A.; Fiket, I.; Steenbergen, M.; Steiner, J. Deliberative and Non-Deliberative Persuasion: Mechanisms of Opinion Formation in EuroPolis. Eur. Union Politics 2016, 153, 410-429. [CrossRef]

34. Barber, B. Strong Democracy; University of California Press: Berkeley, CA, USA, 1984.

35. Goodin, R.E.; Niemeyer, S. When Does Deliberation Begin? Internal Reflection Versus Discussion in Deliberative Democracy. Political Stud. 2003, 51, 627-649. [CrossRef]

36. Goodin, R. Democratic Deliberation Within. In Debating Deliberative Democracy; Fishkin, J., Laslett, P., Eds.; Blackwell: Oxford, UK, 2003; pp. 54-79.

37. Goodin, R.E. Democratic Deliberation Within. Philos. Public Aff. 2000, 29, 81-109. [CrossRef]

38. Chambers, S. Reasonable Democracy: Jurgen Habermas and the Politics of Discourse; Cornell University Press: London, UK, 1996.

39. Setälä, M.; Herne, K. Normative theory and experimental research in the study of deliberative mini-publics. In Deliberative Mini-Publics: Involving Citizens in the Democratic Process; Grönlund, K., Bächtiger, A., Setälä, M., Eds.; ECPR Press: Colchester, UK, 2014; pp. 57-75.

40. Böker, M.; Elstub, S. The Possibility of Critical Mini-Publics: Realpolitik and Normative Cycles in Democratic Theory. Representation 2015, 51, 125-144. [CrossRef] 
41. Goodin, R.E. Innovating Democracy: Democratic Theory and Practice after the Deliberative Turn; Oxford University Press: Oxford, UK, 2008.

42. Strandberg, K.; Berg, J. When Reality Strikes: Opinion Changes among Citizens and Politicians during a Deliberation on School Closures. Int. Political Sci. Rev. 2019, 41, 567-583. [CrossRef]

43. Gastil, J.; Black, L.; Moscovitz, K. Ideology, Attitude Change, and Deliberation in Small Face-to-Face Groups. Political Commun. 2008, 25, 23-46. [CrossRef]

44. Smith, G. Democratic Innovations: Designing Institutions for Citizen Participation; Cambridge University Press: Cambridge, UK, 2009.

45. Hendriks, C. Consensus Conferences and Planning Cells: Lay Citizen Deliberations. In The Deliberative Democracy Handbook: Strategies for Effective Civic Engagement in the 21st Century; Gastil, J., Levine, P., Eds.; Josey-Bass: San Francisco, CA, USA, 2005; pp. 80-110.

46. Dryzek, J.S. Foundations and Frontiers of Deliberative Governance; Oxford University Press: Oxford, UK, 2010.

47. Coote, A.; Lenaghan, J. Citizens' Juries: Theory into Practice; IPPR: London, UK, 1997.

48. McIver, S. An. Evaluation of the King's Fund Citizens' Juries Programme; Health Services Management Centre: Birmingham, UK, 1997.

49. Stewart, J.; Kendell, E.; Coote, A. Citizens' Juries; IPPR: London, UK, 1994.

50. Parkinson, J. Deliberating in the Real World: Problems of Legitimacy in Deliberative Democracy; Oxford University Press: Oxford, UK, 2006.

51. French, D.; Laver, M. Participation, bias, durable opinion shifts and sabotage through withdrawal in citizens' juries. Political Stud. 2009, 57, 422-450. [CrossRef]

52. Esterling, K.; Fung, A.; Lee, T. When Deliberation Produces Persuasion rather than Polarization: Measuring and modeling Small Group Dynamics in a Field Experiment. Br. J. Political Sci. 2019, 51, 666-684. [CrossRef]

53. Kahneman, D. Thinking, Fast and Slow; Farrar, Straus and Giroux: New York, NY, USA, 2011.

54. Gerber, M.; Bächtiger, A.; Shikano, S.; Reber, S.; Rohr, S. Deliberative abilities and influence in a transnational deliberative poll (EuroPolis). Br. J. Political Sci. 2018, 48, 1-26. [CrossRef]

55. Himmelroos, S.; Christensen, H.S. Deliberation and Opinion Change: Evidence from a Deliberative Mini-public in Finland. Scand. Political Stud. 2013, 37, 41-60. [CrossRef]

56. Herne, K.; Christensen, H.S.; Grönlund, K. The influence of political knowledge on opinion polarization in citizen deliberation. Political Res. Exch. 2019, 1,1-23. [CrossRef]

57. Shapiro, I. The State of Democratic Theory; Princeton University Press: Princeton, NJ, USA, 2003.

58. Mutz, D.C. Hearing the Other Side: Deliberative versus Participatory Democracy; Cambridge University Press: Cambridge, UK, 2006.

59. Jordan, G. Policy without Learning: Double Devolution and Abuse of the Deliberative Idea. Public Policy Adm. 2007, 22, 48-73. [CrossRef]

60. Sanders, L.M. Making Deliberation Cooler. Good Soc. 2010, 19, 41-47. [CrossRef]

61. Sanders, D. The Effects of Deliberative Polling in an EU-Wide Experiment: Five Mechanisms in Search of an Explanation. Br. J. Political Sci. 2012, 42, 617-640. [CrossRef]

62. Luskin, R.C.; Fishkin, J.S.; Jowell, R. Considered Opinions: Deliberative Polling in Britain. Br. J. Political Sci. 2002, 32, $455-487$. [CrossRef]

63. Fournier, P.; van der Kolk, H.; Carty, K.; Blais, A.; Rose, J. When Citizens Decide: Lessons from Citizen Assemblies on Electoral Reform; Oxford University Press: Oxford, UK, 2011.

64. Kinder, B.N.; Pape, N.E.; Walfish, S. Drug and Alcohol Education Programmes: A Review of Outcome Studies. Subst. Use Misuse 1980, 15, 1035-1054.

65. Andersen, V.N.; Hansen, K.M. How Deliberation Makes Better Citizens: The Danish Deliberative Poll on the Euro. Eur. J. Political Res. 2007, 46, 531-556. [CrossRef]

66. Farrar, C.; Fishkin, J.S.; Green, D.P.; List, C.; Luskin, R.C.; Paluck, E.L. Disaggregating Deliberation's Effects: An Experiment within a Deliberative Poll. Br. J. Political Sci. 2010, 40, 333-347. [CrossRef]

67. Suiter, J.; Farrell, D.M.; O'Malley, E. When Do Deliberative Citizens Change Their Opinions? Evidence from the Irish Citizens' Assembly. Int. Political Sci. Rev. 2016, 37, 198-212. [CrossRef]

68. Farrell, D.; O'Malley, E.; Suiter, J. Deliberative Democracy in Action Irish-style: The 2011 We the Citizens pilot citizens' assembly. Ir. Political Stud. 2013, 28, 99-113. [CrossRef]

69. O'Malley, E.; Farrell, D.M.; Suiter, J. Does talking matter? A quasi-experiment assessing the impact of deliberation and information on opinion change. Int. Political Sci. Rev. 2020, 41, 321-334. [CrossRef]

70. Curato, N.; Dryzek, J.S.; Ercan, S.A.; Hendriks, C.M.; Niemeyer, S. Twelve key findings in deliberative democracy research. Dædalus 2017, 146, 28-38. [CrossRef]

71. Sturgis, P.; Roberts, C.; Allum, N. A Different Take on the Deliberative Poll: Information, Deliberation and Attitude Constraint. Public Opin. Q. 2005, 69, 30-65. [CrossRef]

72. Grönlund, K.; Herne, K.; Setälä, M. Does Enclave Deliberation Polarize Opinions? Political Behav. 2015, 37, 995-1020. [CrossRef]

73. Farrar, C.; Green, D.P.; Green, J.E.; Nickerson, D.W.; Shewfelt, S. Does Discussion Group Composition Affect Policy Opinions? Results from Three Randomized Experiments. Political Psychol. 2009, 30, 615-647. [CrossRef] 
74. Strachan, P.; Lal, D. Wind Energy Policy, Planning and Management Practice in the UK: Hot Air or a Gathering Storm? Reg. Stud. 2004, 38, 549-569. [CrossRef]

75. Warren, C.R.; Lumsden, C.; O’Dowd, S.; Birnie, R.V. 'Green on Green': Public perceptions of wind power in Scotland and Ireland. J. Environ. Plan. Manag. 2005, 48, 853-875. [CrossRef]

76. Wolsink, M. Planning of Renewables Schemes: Deliberative and Fair Decision-Making on Landscape Issues instead of Reproachful Accusations of Non-Cooperation. Energy Policy 2007, 35, 2692-2704. [CrossRef]

77. Langer, K.; Decker, T.; Menrad, K. Public participation in wind energy projects located in Germany: Which form of participation is the key to acceptance? Renew. Energy 2017, 112, 63-73. [CrossRef]

78. Escobar, O.; Faulkner, W.; Rea, H. Building capacity for dialogue facilitation in public engagement around research. J. Dialogue Stud. 2014, 2, 87-111.

79. Teddlie, C.; Tashakkori, A. Foundations of Mixed Methods Research: Integrating Quantitative and Qualitative Approaches in the Social and Behavioral Sciences; Sage: London, UK, 2009.

80. Finkel, S.E. Causal analysis with panel data; Sage: London, UK, 1995.

81. Gerring, J. How Good Is Good Enough? A Multidimensional, Best-Possible Standard for Research Design. Political Res. Q. 2011, 64, 625-636. [CrossRef]

82. Freese, J.; Peterson, D. Replication in Social Science. Annu. Rev. Sociol. 2017, 43, 147-165. [CrossRef]

83. Sunstein, C.R. Going to Extremes: How Like Minds Unite and Divide; Oxford University Press: Oxford, UK, 2009.

84. Haggett, C. Public Engagement in Planning for Renewable Energy. In Planning for Climate Change: Strategies for Mitigation and Adaptation for Spatial Planners; Davoudi, S., Crawford, J., Eds.; Earthscan: London, UK, 2009; pp. 297-307.

85. Wüstenhagen, R.; Wolsink, M.; Bürer, M.J. Social Acceptance of Renewable Energy Innovation: An Introduction to the Concept. Energy Policy 2007, 35, 2683-2691. [CrossRef]

86. Devine-Wright, P. Rethinking NIMBYism: The Role of Place Attachment and Place Identity in Explaining Place-protective Action. J. Community Appl. Soc. Psychol. 2009, 19, 426-441. [CrossRef]

87. Flyvbjerg, B. Five misunderstandings about case-study research. Qual. Inq. 2006, 12, 219-245. [CrossRef] 